\title{
Potentiation of cytotoxicity by combination of imatinib and chlorimipramine in glioma
}

\author{
AYHAN BILIR $^{1 *}$, MINE ERGUVEN $^{2 *}$, GULPERI OKTEM $^{3}$, AYSEGUL OZDEMIR $^{4}$, \\ ATILLA USLU $^{5}$, ESIN AKTAS ${ }^{6}$ and BENJAMIN BONAVIDA ${ }^{7}$
}

\author{
${ }^{1}$ Department of Histology and Embryology, Istanbul University, Istanbul Faculty of Medicine, Istanbul; \\ ${ }^{2}$ Department of Biochemistry, Istanbul University, Faculty of Pharmacy, Istanbul; ${ }^{3}$ Department of Histology and \\ Embryology, Ege University School of Medicine, Izmir; ${ }^{4}$ Department of Neurosurgery, Bakirkoy Hospital for Psychiatric \\ and Neurological Diseases, Istanbul; ${ }^{5}$ Department of Physiology, Istanbul University, Istanbul Faculty of Medicine, \\ Istanbul; ${ }^{6}$ Department of Immunology, Istanbul University, Institute for Experimental Medicine (DETAE), Istanbul, \\ Turkey; ${ }^{7}$ Department of Microbiology, Immunology and Molecular Genetics, Jonsson Comprehensive \\ Cancer Center, University of California, Los Angeles, CA, USA
}

Received November 19, 2007; Accepted January 7, 2008

\begin{abstract}
Rat C6 glioma is a chemo-resistant experimental brain tumor that is difficult to treat with various drug combinations. Previous studies suggested that imatinib mesylate (Gleevec) is effective in pre-clinical trials for glioblastoma. Also, chlorimipramine (Anafranil) is an anti-depressant drug in use in the clinic and shown to have anti-neoplastic activity. We hypothesized that treatment of resistant C6 glioma with combination of imatinib and chlorimipramine may potentiate cytotoxicity and reverse resistance. C6 glioma was examined both as monolayer and as spheroid cultures. Several experimental designs were examined all of which showed synergistic activity albeit at different time kinetics. Combination treatment resulted in inhibition of cell growth and enhanced cell death as determined by dye exclusion. Further, the combination treatment resulted in significant induction of apoptosis as determined by Annexin V-FITC and PI. Also, there was inhibition of DNA synthesis and cAMP. Altogether, these findings supported the antiproliferative and cytotoxic effects of the combination treatment. Morphological studies were also performed using transmission and scanning electron microscopy. Significant synergistic apoptosis was detected by the combination treatment in both the monolayers and spheroid cultures. There was also a synergistic effect in autophagy by the
\end{abstract}

Correspondence to: Professor Ayhan Bilir, Department of Histology and Embryology, Istanbul University, Istanbul Faculty of Medicine, 34093 Capa, Istanbul, Turkey

E-mail: bilira@istanbul.edu.tr

${ }^{*}$ Contributed equally

Key words: autophagy, chlorimipramine, C6 glioma, imatinib mesylate, spheroid culture combination. Several altered morphological features were noted by both the individual compound and enhanced by the combination treatment. The present findings support our hypothesis and demonstrate the potentiation of cytotoxicity by the com-bination of imatinib and chlorimipramine in C6 glioma. Further, the findings suggest the potential clinical application of the combination in the treatment of drugresistant glioma.

\section{Introduction}

Receptor and non-receptor tyrosine kinases (TKs) have emerged as clinically useful drug target molecules for treating cancer (1). Imatinib mesylate (IM; STI-571, Gleevec ${ }^{\circledR}$ ) is a small molecule ATP analogue which is a potent and selective inhibitor of several protein TKs of the receptors for plateletderived growth factor (PDGF), bcr-abl, stem cell factor (SCF), and c-kit by interacting with the ATP-binding site $(2,3)$. It has been reported that mitochondria and telomerase are also targets of imatinib mesylate $(4,5)$. IM was primarily designed to treat chronic myeloid leukemia (CML), but it is also currently the drug of choice for the treatment of metastatic gastrointestinal stromal tumors (GISTs) $(6,7)$. The success of this compound in the treatment of CML and GISTs has led to the broader examination of its application in the treatment of other tumors, such as glioblastoma (8), small lung cancer (9), anaplastic thyroid cancer (10) and prostate cancer (11).

C6 rat glioma is a chemo-resistant experimental brain tumor which is difficult to treat with a combination of drugs (12). This cell line has properties similar to human glioblastoma and has been widely used as a model system for investigation of human glioblastoma (13). Imatinib has recently been found to be efficacious in preclinical trials for glioblastoma, but the use of IM has been tempered by the problems of disease persistence and resistance. It has been reported that IM inhibits the growth of glioma cells in preclinical models, but its poor brain distribution by P-glycoprotein $(\mathrm{P}-\mathrm{gp})$ limits its efficacy in patients $(14,15)$. 
Chlorimipramine (CIMP; clomipramine or Anafranil ${ }^{\circledR}$ ) is the tricyclic anti-depressant that has been in clinical use for over 30 years (16). Previous studies which were made on various types of cancer cells, including drug-resistant leukemias, renal cancer cells, solid murine tumors, and a wide range of cell cultures derived from brain tumors, (e.g., astrocytomas, mixed oligo-astrocytomas, glioblastoma multiforme, and menningiomas), revealed the novel effect of CIMP as an anti-neoplastic agent (17-20). From studies carried out on non-tumorigenic tissues and tumorigenic cell lines, it has been shown that CIMP inhibits complex-III of the respiratory chain, resulting in increased ROS, cytochrome $\mathrm{C}$ release and caspase-activated apoptosis $(21,22)$. CIMP also causes irreversible DNA damage in both normal and neoplastic cells, but mitochondria damage has only been observed in neoplastic cells (19). CIMP has been demonstrated to reverse multidrug resistance (MDR) to conventional antineoplastic agents, such as doxorubicin, in several tumor cell lines in vitro $(17,19,23,24)$.

One of the most recent novel developments in chemotherapy has been to move away from cytotoxic agents that inhibit non-specific targets in cellular pathways that contribute to carcinogenesis and resistance $(25,26)$. The present study investigated the therapeutic potential of the selective mitochondria inhibitor, CIMP, used in combination with IM for the treatment of malignant C6 glioma cells used as monolayers and spheroid cultures. This combination of IM and CIMP has not been previously investigated in vitro or in vivo.

\section{Materials and methods}

Drugs and solutions. The following drugs were used: IM was kindly provided by Dr E. Buchdunger (Novartis AG, Basel, Switzerland) and Dr Fulya Dincturk (Novartis AG, Istanbul, Turkey). CIMP was obtained from Boehringer (Mannheim, $\mathrm{GmbH})$. IM was prepared as $100 \mu \mathrm{M}$ stock solution in phosphate buffered saline ( $\mathrm{pH}$ 7.2) and filtered through a $0.22 \mu$ injector filter (TPP, Trasadingen, Switzerland) before use. CIMP was dissolved in $70 \%$ ethanol to give a stock solution of $100 \mu \mathrm{M}$.

Monolayer culture. The rat C6 glioma cell line was supplied by ATCC (Rockville, MD, USA) and was grown in monolayers in Dulbecco's Modified Eagle's Medium-F12 (DMEMF12; Biological Industries, Haemek, Israel) supplemented with $10 \%$ heat-inactivated foetal calf serum (FCS; Sigma Chemical Co., St. Louis, MO, USA), 100 units/ml penicilin and $100 \mu \mathrm{g} / \mathrm{ml}$ streptomycin (both from Sigma Chemical Co.). Cells in semi-confluent flasks were harvested by using $0.05 \%$ trypsin (Sigma Chemical Co.), centrifuged after adding DMEM-F12 for trypsin inactivation, and resuspended in DMEM-F12. After trypan blue exclusion, the glioma cells were plated in 6-well culture plates containing $5 \mathrm{ml}$ DMEMF12 medium at a concentration of $5 \times 10^{5}$ cells/well with $100 \%$ viability.

Constitution of a 3-dimensional spheroid model. An in vitro multicellular C6 glioma spheroid model was established using the liquid overlay technique. Briefly, once the monolayer cultures became semi-confluent, the cells were trypsinized and single cells with $100 \%$ viability were cultured over 3\% Difco Noble agar-coated (Becton-Dickinson, Sparks, MD) 6-well culture plates containing $5 \mathrm{ml}$ DMEM-F12 medium at a concentration of $1 \times 10^{6}$ cells/well (27).

Experimental design. The investigated drugs at a volume of $100 \mu 1$ were applied to monolayers and spheroid cultures of malignant C6 glioma cells at the following final concentrations: $1,10,100$ and $200 \mu \mathrm{M}$, except for the control cells, to which nutrient medium was applied. The cultures were incubated for 24, 48, 72 and $96 \mathrm{~h}$. The $\mathrm{IC}_{50}$ values of IM and CIMP were determined as $10 \mu \mathrm{M}$. Four sets of experiments were performed under the following standard monolayer and spheroid culture conditions: i) untreated control cells; ii) cells treated with IM; iii) cells treated with CIMP; and iv) cells treated with a combination of IM and CIMP at a ratio of 1:1. The effects of drugs, both on monolayers and spheroid cultures, were determined by evaluation of cytotoxicants, including cell proliferation (total cell number), cell viability by trypan blue exclusion assay, the bromodeoxyuridine labelling index (BrDU-LI), spheroid volumes, morphology by transmission (TEM) and scanning (SEM) electron microscopy, Annexin V-FITC/PI staining, and cAMP levels by radioimmunoassay.

\section{Cell cycle kinetics}

Analysis of DNA synthesis (S-phase) by BrdU incorporation for monolayer cultures. C6 rat glioma cells were seeded on the cover slips and treated with drugs, as described in the survival studies throughout $96 \mathrm{~h}$ at 24 -h intervals. Endogenous peroxidase activity was quenched with $0.5 \% \quad \mathrm{H}_{2} \mathrm{O}_{2}$ in methanol. Double-stranded DNA was denatured with $4 \mathrm{~N} \mathrm{HCl}$. Following the washings, a non-specific blocking reagent (Ultra-V-Block; Lab Vision Co., Westinghouse, CA, USA) was used to prevent non-specific binding. Monoclonal mouse anti-BrdU antibody (1:50; Lab Vision Co.) was the primary antibody and the secondary antibody was biotinylated goat anti-mouse antibody (Lab Vision Co.). After washing, peroxidase-conjugated streptavidin (Lab Vision Co.) was applied and aminoethyl carbazole was used as a chromogen. The cover slips were then counterstained with Mayer's hematoxylin to augment the nuclear staining. BrDUlabelled cells in the S-phase had red-stained nuclei. For negative controls, the cover slips of the same groups were processed with exactly the same steps, excluding the primary antibody. The BrDU-LI (the number of positively stained cells divided by the counted total number of cells) was calculated by evaluating at least 3000 cells in multiple high power fields.

DNA synthesis (S-phase) analysis by BrdU incorporation for spheroid cultures. Spheroids were gently removed from the surface of the solidified agarose. The sections were treated with $0.1 \%$ trypsin for antigen retrieval and incubated in a solution of $0.3 \% \mathrm{H}_{2} \mathrm{O}_{2}$. The sections were treated with $4 \mathrm{~N}$ $\mathrm{HCl}$ and incubated in $0.1 \mathrm{M}$ Borax. Following the washings, a non-specific blocking reagent (Ultra-V-Block; Lab Vision Co.) was used to prevent non-specific binding. Monoclonal mouse anti-BrdU antibody (1:50; Lab Vision Co.) was the 
primary antibody and the secondary antibody was a biotinylated goat anti-mouse antibody (Lab Vision Co.). After washing, peroxidase-conjugated streptavidin (Lab Vision Co.) was applied and aminoethyl carbazole was used as a chromogen. The sections were counterstained in Mayer's hematoxylin. BrDU-labelled cells in S-phase had red-stained nuclei. Approximately 30 spheroids in each slide were determined for the calculation of the BrDU-LI. For negative controls, adjacent sections were processed with exactly the same steps, excluding the primary antibody.

Annexin V-FITC/PI staining. One of the manifestations of apoptosis is the translocation of phosphotidylserine (PS) from the inner membrane to the outer side of the plasma membrane. Externalization of PS was studied by an Annexin $\mathrm{V}$ binding assay. Briefly, cells were washed with PBS twice and re-suspended in binding buffer containing 0.01 M HEPES, $0.14 \mathrm{mM} \mathrm{NaCl}$ and $2.5 \mathrm{Mm} \mathrm{CaCl}_{2}$. A cell suspension $\left(1 \times 10^{5}\right.$ cells in $100 \mu \mathrm{l}$ ) in the binding buffer was incubated with $5 \mu \mathrm{l}$ of FITC-labeled Annexin V (BD PharMingen, San Diego, $\mathrm{CA}$ ) and vital dye propidium iodide for $15 \mathrm{~min}$ in the dark at room temperature. After incubation, the fluorescence of the cells for propidium iodide (PI) and Annexin V was measured simultaneously in a BD FACS Calibur and analyzed with the operating software of the instruments (CellQuest; BD PharMingen). Data acquisition and analysis were done with the CellQuest and WinMDI programs.

cAMP levels. Following centrifugation of cultures, the supernatants were removed and $0.1 \mathrm{~N} \mathrm{HCl}$ with DMEM-F12 medium (1:1) was added to the cells to stop the reaction at each 24-h interval until $96 \mathrm{~h}$. Briefly, $25 \mu \mathrm{l}$ of the samples was used to measure cAMP levels. cAMP accumulation was measured in the supernatants, as described previously with some modifications (28). cAMP was determined by radioimmunoassay using the acetylation protocol (29). High-affinity rabbit anti-cAMP antibody was raised in our laboratory by using BSA-conjugated cAMP. Succinyl-cAMP tyrosine methylester (ScAMP-TME) was iodinated by the chloramine-T method (30). Mono- and di-iodo ScAMP-TME were used as tracer ligands for radioimmunoassay and they were then purified by gel-filtration chromatography (Sephadex G 25 superfine), equilibrated and eluted with $1 \mathrm{M}$ sodium acetate ( $\mathrm{pH}$ 5.0). Results are given as $\mathrm{pmol} / \mathrm{ml}$.

Transmission electron microscopy. Harvested spheroids were fixed with $2.5 \%$ glutaraldehyde in $0.1 \mathrm{M}$ sodium cacodylate buffer and post-fixed in $1 \%$ osmium tetraoxide in $0.1 \mathrm{M}$ sodium cacodylate buffer for $1 \mathrm{~h}$ at $4^{\circ} \mathrm{C}$. Cells were incubated in $1 \%$ uranyl acetate for $1 \mathrm{~h}$ at $4^{\circ} \mathrm{C}$, dehydrated in a graded acetone series and embedded in Epon 812. Samples were cut on a microtome (Leica MR 2145, Heerbrugg, Switzerland) and $70-\mathrm{nm}$ thick sections were mounted on copper grids. They were stained with 5\% uranyl acetate and counterstained with Reynold's lead citrate. Sections were examined with a Jeol-Jem 1011 transmission electron microscope.

Scanning electron microscopy. C6 glioma cells were seeded on microslides in 24-well cultures plates containing $1 \mathrm{ml}$ DMEM-F12 medium at a concentration of $5 \times 10^{4}$ cells/well.
After attachment of the cells, drugs in a concentration of $10 \mu \mathrm{M}$ alone and in combination, were applied to cells. Cells were fixed with $2.5 \%$ glutaraldehyde in $0.1 \mathrm{M}$ sodium cacodylate buffer ( $\mathrm{pH} 7.4$ ) for $1 \mathrm{~h}$ at $4^{\circ} \mathrm{C}$ at the 24 and $72 \mathrm{~h}$. Cells were washed twice for $10 \mathrm{~min}$ with $0.1 \mathrm{M}$ sodium cacodylate buffer and post-fixed in $1 \%$ osmium tetraoxide for $1 \mathrm{~h}$ at $4^{\circ} \mathrm{C}$. Cells were dehydrated in graded acetone series and incubated in amyl acetate. Microslides were critical-point dried, sputter coated with gold-palladium and observed by SEM (JeolJSM-5200; Jeol, Tokyo, Japan) Photographs were taken at $25 \mathrm{kV}$ using various magnifications and angles.

Statistical analysis and determination of synergism. SPSS 12.0 statistical software (SPSS, Inc., Chicago, IL, USA) was used for the statistical analysis. The statistical comparison of all results, except for cAMP levels, were analyzed by using the Student's t-test. Alterations in cAMP levels were analyzed by one-way ANOVA test with post hoc analysis using Tukey HSD at the $24 \mathrm{~h}$ and the Welch test with Dunnett T3 test at the $72 \mathrm{~h}$. Data are represented as the mean \pm SEM or SD, as appropriate, for at least three separate experiments. Results were considered significant with $\mathrm{p}<0.0005, \mathrm{p}<0.001$, $\mathrm{p}<0.01$ and $\mathrm{p}<0.05$.

Synergy was determined as described previously (31-33). By this method, synergism was detemined using the following equation: $\mathrm{CI}=\left(\mathrm{D}_{1}\right) /\left(\mathrm{D}_{\mathrm{X}}\right) 1+\left(\mathrm{D}_{2}\right) /\left(\mathrm{D}_{\mathrm{X}}\right)_{2}$, where $\mathrm{D}_{1}$ is the tested concentration of IM used in combination with CIMP, $\mathrm{D}_{2}$ is the tested concentration of CIMP used in combination with $\mathrm{IM}, \mathrm{DX}$ is the concentration of IM alone and $(\mathrm{DX})_{2}$ is the concentration of CIMP alone. A CI value of 1 indicated an additive effect, a CI value $<1$ indicated a synergistic effect and a $C$ I value $>1$ suggested an antagonistic effect.

\section{Results}

Cell proliferation. The effects of single and combination drugs on cell proliferation of C6 glioma is shown in Fig. 1A. The cell number of the control group showed a proportional increase as a function of incubation time up to $96 \mathrm{~h}$. In comparison to the control group, all drug treatments reduced the number of cells at all times throughout different rates. Treatment of cells with IM and CIMP resulted in a potent reduction in the number of cells after $72 \mathrm{~h}$ by 54 and $87 \%$, respectively $(\mathrm{p}<0.001$ and $\mathrm{p}<0.0005$, respectively). The combination of IM and CIMP caused a 45, 81, 89 and $87 \%$ reduction for different times of incubation $(\mathrm{p}<0.05, \mathrm{p}<0.01$, $\mathrm{p}<0.001$ and $\mathrm{p}<0.01$, respectively). The reduction values of $\mathrm{IM}$ and the combination group were different from each other after the first $24 \mathrm{~h}(\mathrm{p}<0.01, \mathrm{p}<0.05$ and $\mathrm{p}<0.0001$, respectively). In contrast, the reduction in the number of cells following CIMP treatment and the combination group was different from each other only at $48 \mathrm{~h}$ following treatment $(\mathrm{p}<0.05)$. The inhibition by the combination group on cell proliferation was synergistic at $96 \mathrm{~h}$.

Cell viability. The cell viability of the group was $90 \%$ at $24 \mathrm{~h}$ and up to $99 \%$ at $96 \mathrm{~h}$. Both single and combination treatments reduced the cell viability through $48 \mathrm{~h}$; the most effective in reducing cell viability was the combination group $(13 \%, \mathrm{p}<0.05)$. After $48 \mathrm{~h}$, all drug treatments lost their 

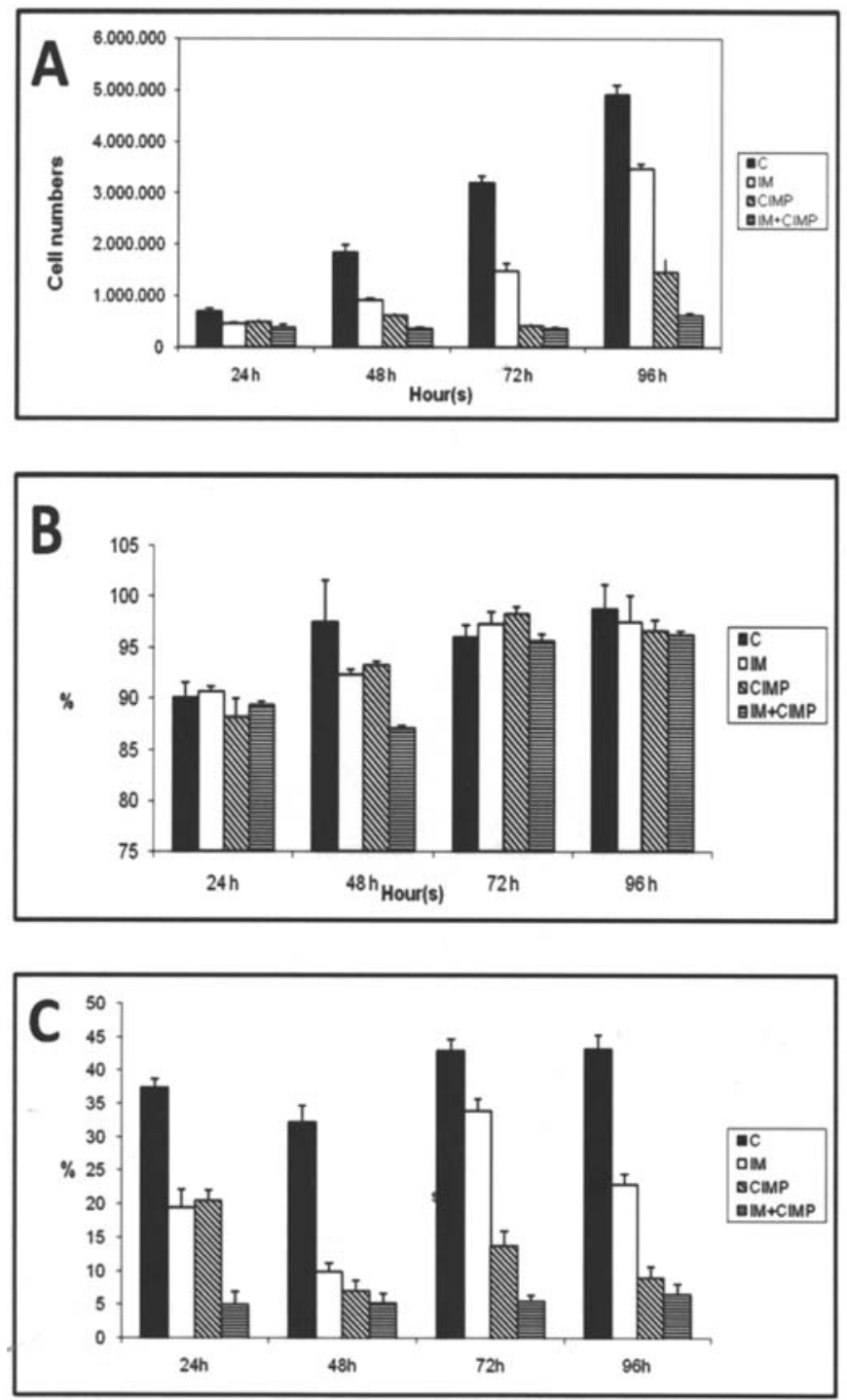

Figure 1. Growth, viability and BrDU-LI of monolayer cultured C6 glioma cells treated with imatinib and chlorimipramine at a concentration of $10 \mu \mathrm{M}$ for $96 \mathrm{~h}$. Cells were initially plated at a seeding density of $5 \times 10^{5}$ cells per well. (A) Cell proliferation, (B) Cell viability, (C) BrDU-LI. C, control; IM, imatinib; CIMP, chlorimipramine; IM+CIMP, imatinib with chlorimipramine. Results are the mean of 3 different experiments and given as mean $\pm \mathrm{SE}$.

inhibitory effect on cell viability and the percentage of trypan blue-positive cells were the same and/or similar to the control group and to each other (97, 97 and $96 \%$ at the $96 \mathrm{~h}$ for the IM, CIMP and combination groups, respectively; Fig. 1B).

\section{Cell cycle kinetics}

DNA synthesis (S-phase) analysis of monolayer cultures. Cells with red-stained nuclei were considered BrDU-positive. As shown in Fig. 1C, C6 glioma cell nuclei were positive for $\mathrm{BrDU}$ in the control group with BrDU-LI values of $37.53 \%$ at $24 \mathrm{~h}$ and $43.26 \%$ at $96 \mathrm{~h}$. Treatment of cells with IM and CIMP resulted in a potent reduction of BrDU-LI values at 48 and $96 \mathrm{~h}$, with values of 69 and $79 \%$, respectively ( $\mathrm{p}>0.05)$. Combining IM with CIMP did not have much effect on the BrDU-LI throughout the $96 \mathrm{~h}$ of culture and the potent inhibition of the BrDU-LI value (87\%) persisted at 24 and $48 \mathrm{~h}(\mathrm{p}<0.05)$. The decrease of BrDU-LI by the combination represented a synergistic effect at 24 and $72 \mathrm{~h}$.

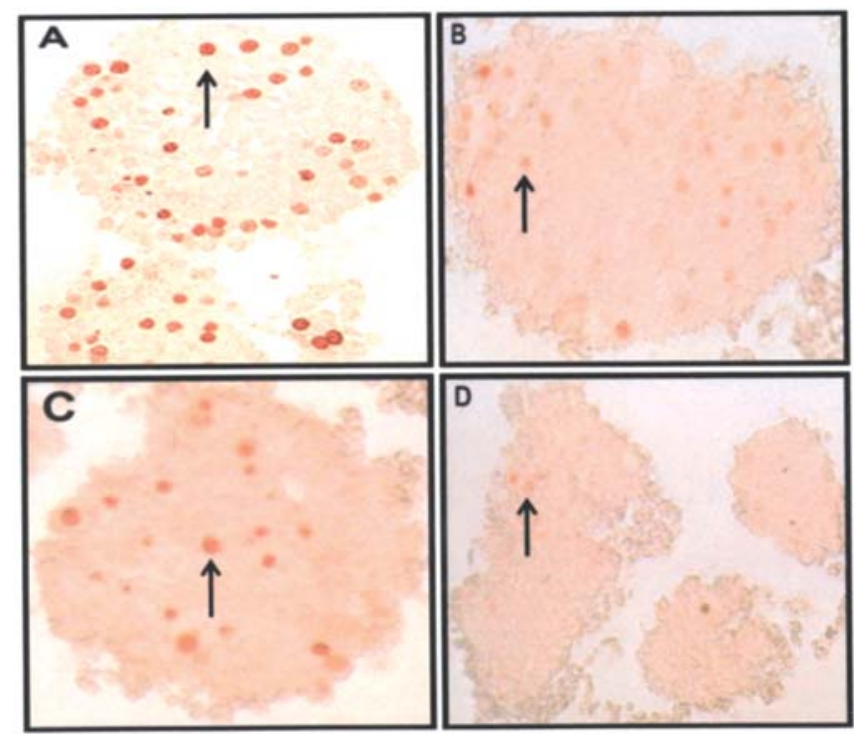

Figure 2. BrDU results of the spheroid culture of rat C6 glioma cells at $24 \mathrm{~h}$. Cells with red stained nucleus were considered BrDU positive. Arrows show BrDU positive cells. (A) Control group (original magnification, x25), (B) Imatinib (original magnification, x40), (C) Chlorimipramine (original magnification, x25), (D) Imatinib with chlorimipramine (original magnification, $\mathrm{x} 25)$.

DNA synthesis (S-phase) analysis for spheroid cultures. Twenty-five spheroids from all experimental groups, including the control group, were evaluated for $24 \mathrm{~h}$. Cells with redstained nuclei were considered BrDU-positive. The control group had a healthy pattern of S-phase fraction and many of the C6 glioma cell nuclei were observed to be positive for BrDU with a BrDU-LI value of $8.7 \%$ (Fig. 2A). In comparison to controls, IM and CIMP alone reduced the BrDU-LI values to 3.72 and $2.43 \%$, respectively. In addition, light microscopy photographs supported this statistical values that the spheroids of IM and CIMP groups showed less BrDU-LI positive C6 glioma cells (Fig. 2B and C). When the combination group was compared with the control group, a decrease in the BrDU-LI value to $1.96 \%$ was observed. In comparison to the other drug groups, the combination group seemed to have no significant difference as the BrDU-LI value was very similar to the CIMP group (Fig. 2D). In comparison to the controls, either drug treatment alone or in combination was not statistically significant.

Annexin V-FITC and PI double staining. Fig. 3 clearly shows different levels of apoptosis induced by the two agents when used singly. The percentage of apoptotic cells in the IM group (14.19\%) was modestly increased when compared with the control group $(9.82 \%)$ at $24 \mathrm{~h}$, but at $96 \mathrm{~h}$ treatment with IM decreased the percentage of the apoptotic cells to $9.09 \%$. In comparing the control group and the IM group, CIMP potently induced apoptosis i.e., 35.49 and $80.49 \%$ at 24 and $96 \mathrm{~h}$, respectively. However, when IM with CIMP were used, the level in combination of apoptosis was enhanced and greater than additive $(61.95 \%)$ at $24 \mathrm{~h}$. The percentage of apoptotic cells induced by the combination group $(86.52 \%)$ were similar to the CIMP group $(80.49 \%)$ at $96 \mathrm{~h}$.

cAMP levels. The cAMP levels of the control group showed a proportional increase from $8.20 \mathrm{pmol} / \mathrm{ml}$ at time 0 to 37.47 
24 HOURS

A

C

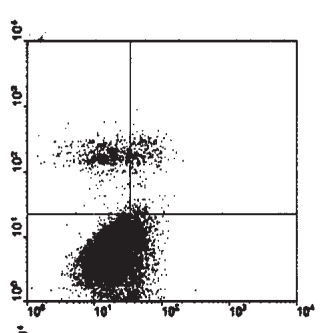

IM

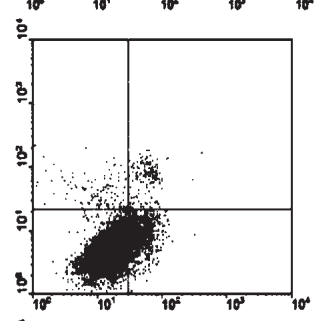

CIMP
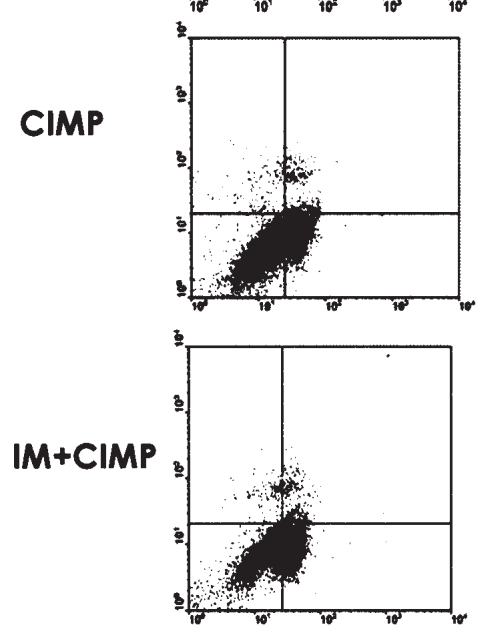

96 HOURS

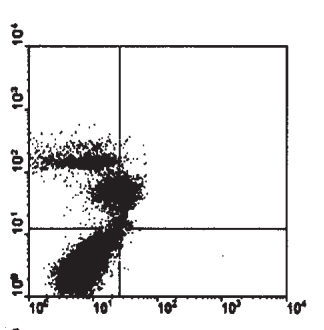

$:$
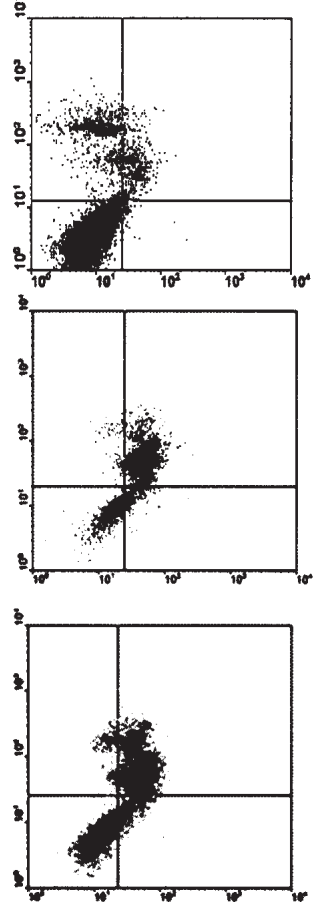

$\mathrm{pmol} / \mathrm{ml}$ at $24 \mathrm{~h}$ and $61.61 \mathrm{pmol} / \mathrm{ml}$ at the $72 \mathrm{~h}$. cAMP levels of the IM group $(37.68 \mathrm{pmol} / \mathrm{ml})$ were almost the same as the control group at $24 \mathrm{~h}$, but IM inhibited cAMP levels similar to the control $(31.26 \mathrm{pmol} / \mathrm{ml})$ at $72 \mathrm{~h}(\mathrm{p}<0.05)$. In comparison to the control and IM groups, CIMP potently decreased cAMP levels to $19.14 \mathrm{pmol} / \mathrm{ml}$ at $24 \mathrm{~h}(\mathrm{p}<0.05)$ and $2.68 \mathrm{pmol} / \mathrm{ml}$ at $72 \mathrm{~h}(\mathrm{p}<0.01)$. The combination of IM with CIMP mildly decreased the levels to $30.40 \mathrm{pmol} / \mathrm{ml}$ at $24 \mathrm{~h}(\mathrm{p}>0.05)$, but this group potently decreased cAMP levels to $5.19 \mathrm{pmol} / \mathrm{ml}$ at $72 \mathrm{~h}(\mathrm{p}<0.01)$. The most potent inhibitory effect among all drug treatments and time intervals was observed in the CIMP group (Fig. 4).

Morphology. We discriminated the ultrastructural differences between the control group and the drug-applied groups by using TEM and SEM.

\section{Spheroid morphology by TEM}

$24 \mathrm{~h}$ of culture. The control group exhibited normal morphology, characterized by fine texture of nuclear chromatin defined as oval, heterochromatic nuclei, intact nuclear membrane, a cytoplasm rich in secretory materials, proportional organelles distributed in the cytoplasm, tubular structure of mitochondria, intact cytoplasmic membrane, and many microvilli, which were in contact with other cells (Fig. 5A). The IM-treated group exhibited a smoothing of the cell surface, characterized with decreased, short microvilli,

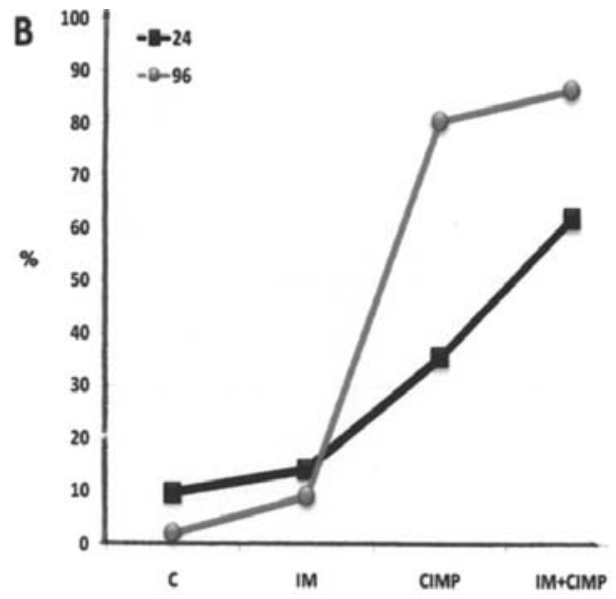

Figure 3. The effects of drugs on C6 glioma cells were discriminated by flow cytometric data obtained using Annexin V-FITC and PI double stain. (A) Cells were treated with drugs for a total period of $96 \mathrm{~h}$. Cells were harvested at 24 and $96 \mathrm{~h}$. The quadrants within the panel shows: bottom left live non-apoptotic cells (Annexin V negative, PI negative), bottom right cells in early apoptotic phase (Annexin V positive, PI negative); top right mid-phase apoptotic (Annexin V positive, PI positive), top left dead/late apoptotic phase cells (PI positive, Annexin V negative). (B) The percentage of apoptotic cells is plotted (\%). C, control; IM, imatinib; CIMP, chlorimipramine; IM+CIMP, imatinib + chlorimipramine.

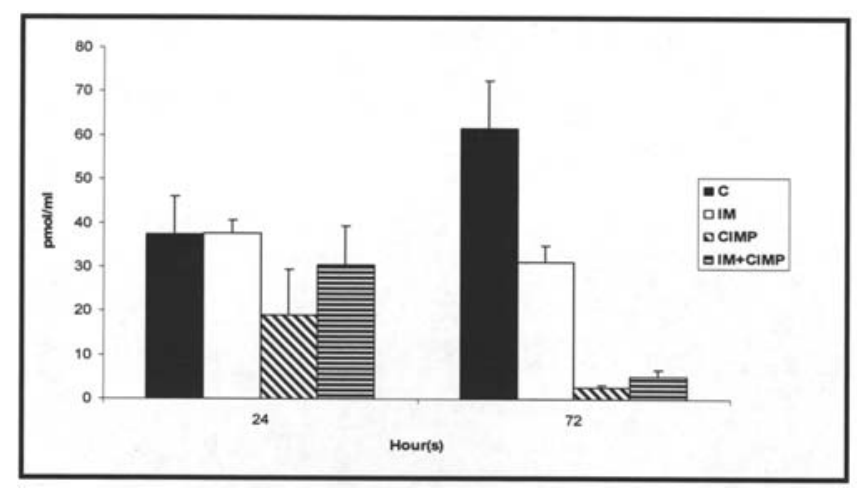

Figure 4. The effects of drugs on cAMP levels of C6 glioma cells were determined by radioimmunoassay using the acetylation protocol. Results are given as $\mathrm{pmol} / \mathrm{ml}$. C, control; IM, imatinib; CIMP, chlorimipramine; IM+CIMP, imatinib + chlorimipramine.

but intact nuclear membrane, pyknotic nuclei, alterations in mitochondria, as delineated by cristae damage and mitochondrial swelling, packaging of small vacuoles, and presumably autophagic vacuoles with lamellar bodies inside, and huge vacuoles, which may be the result of small vacuole fusion. Vacuoles were localized at the peripheral region of the spheroid (Fig. 5B). Mitochondria which possessed outer membrane damage and disrupted or lost cristae were observed in the CIMP group. In addition, presumably autophagic vacuoles, which were in different dimensions with lamellar bodies inside were also seen in this group, similar to the IM group (Fig. 5C). The extension of the nucleus to the cytoplasm, like a pseudopod, was one of the notable finding observed. Apoptotic bodies were also observed by the effect of CIMP. The contact loss of the cells localized at the proliferation zone was the other effect of the drug. The combination of IM with CIMP reflected the total effects of the two drugs displayed when they were administered alone. 

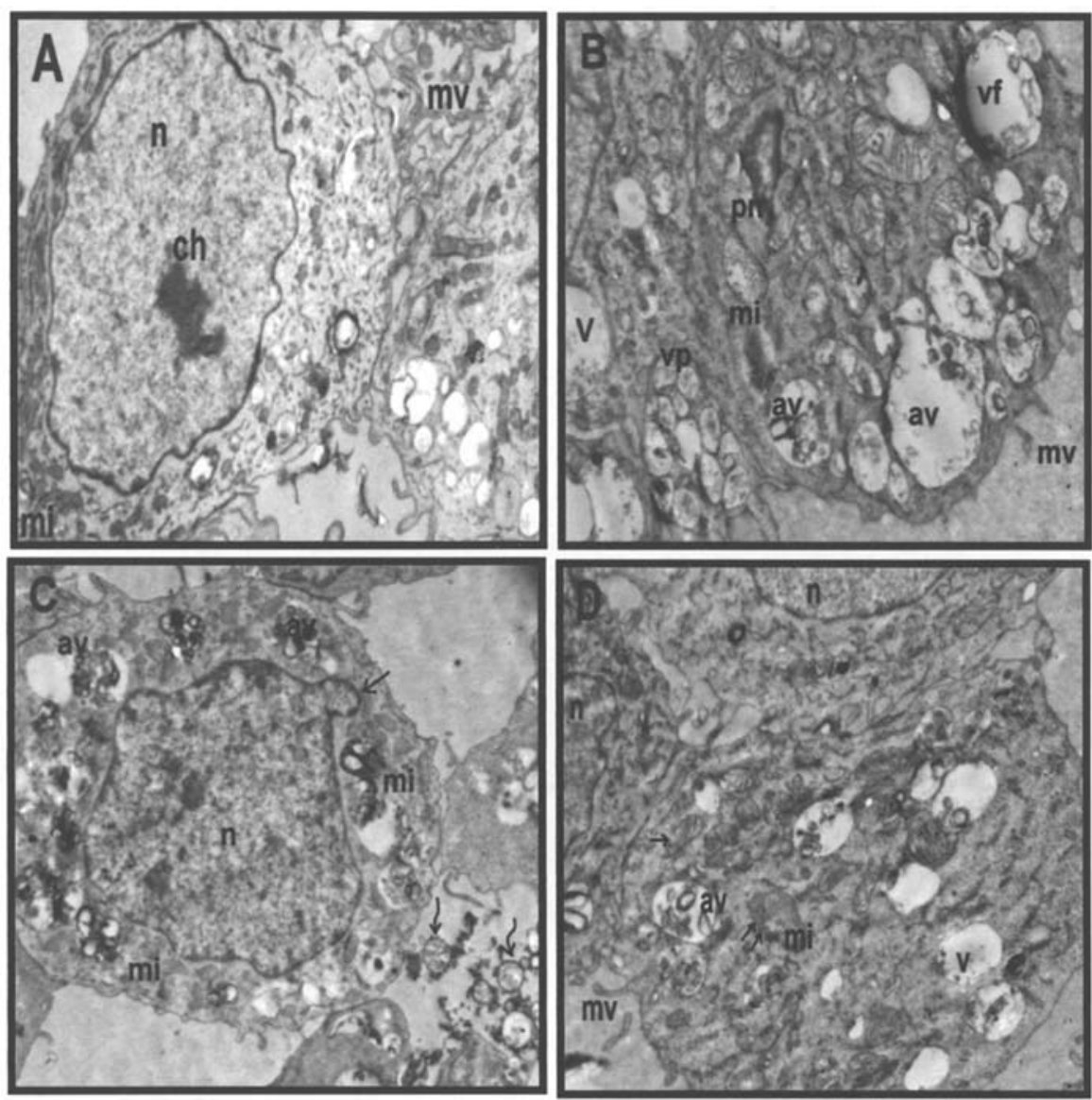

Figure 5. Transmission electron microscopy (TEM) view of C6 glioma spheroids at 24 h. (A) Control group (original magnification, x7500), (B) Imatinib group (original magnification, x12000), (C) Chlorimipramine group (original magnification, x15000). One arrow represents the extention of the nucleus to the cytoplasm like a pseudopod, and wavy arrows represent presumable apoptotic bodies. (D) Imatinib with chlorimipramine. One arrow represents mitochondria with disrupted outer membrane and two arrows represent mitochondria swelling with criastae damage (original magnification, x12000). av, autophagic vacuole; ch, chromatin; $n$, nucleus; mi, mitochondria; mv, microvillus; pn, pyknotic nucleus; v, vacuole; vf, vacuole fusion; vp, package of vacuoles.

Some morphological changes of apoptosis were observed as nuclear fragmentation, increased autophagic vacuoles, mitochondrial damage with disrupted outer membrane and cristae loss and a smooth cell surface (Fig. 5D).

$96 h$ of culture. The presence of a few vacuoles was the only different morphologic alteration observed at $24 \mathrm{~h}$ confined to the control group. The presence of zonula adherens (presumably), endoplasmic reticulum and ribosomes was also noteworthy (Fig. 6A). There were no morphological changes observed in the endoplasmic reticulum regions and cell contact with adjacent cells in the IM-treated group. The same morphological changes were observed as at $24 \mathrm{~h}$, but the degree of mitochodria damage such as cristae loss, membrane loss, and the number of vacuoles (foamy vacuolated cytoplasm), including autophagic vacuoles, was increased in this group at $96 \mathrm{~h}$ (Fig. 6B). Vacuole fusions were also observed. The observed morphologic alterations differed from those at $24 \mathrm{~h}$ and consisted of the increase of autophagic vacuoles in the CIMP group. Separation of the cells localized at the proliferation zone was also observed (Fig. 6C). The combination of IM with CIMP treatment exhibited morphological changes as cell contact loss at the proliferative zone of spheroids, invagination of the nuclear membrane, and the markedly increase in autophagic vacuoles
(Fig. 6D). The presence of big lamellar bodies in the nucleoplasm and plasma membrane fusion was the most interesting features which were observed at that time (Fig. 7A and B). The small components of lytic cells which could be a result of apoptosis were located at the outer part of the spheroid (data not shown).

\section{Cell morphology by SEM}

24 h of culture. The control group of C6 glioma cells had a spindle-shaped appearance and frequent, active mitotic division phase was observed under SEM. In the IM group, cells changed from a spindle-shaped appearance morphology to random formation to an angular morphology. IM led to a decrease in the number of microvilli. Some cells in the IM group possessed cell surface knobs characterized by a protruding surface. In the CIMP group, some cells possessed an angular morphology and some cells changed to a globular appearance like a ball, and CIMP led to a sharp decrease in the number of microvilli and cell surface extensions. In the combination group, three different cell types could be observed as follows: i) a wide body with an angular morphology with short cell surface extensions; ii) a globular appearance like a ball; and iii) cell surface knobs characterized by a protruding surface. Apoptotic bodies were prominent in this group. The presence of three different cell types which 

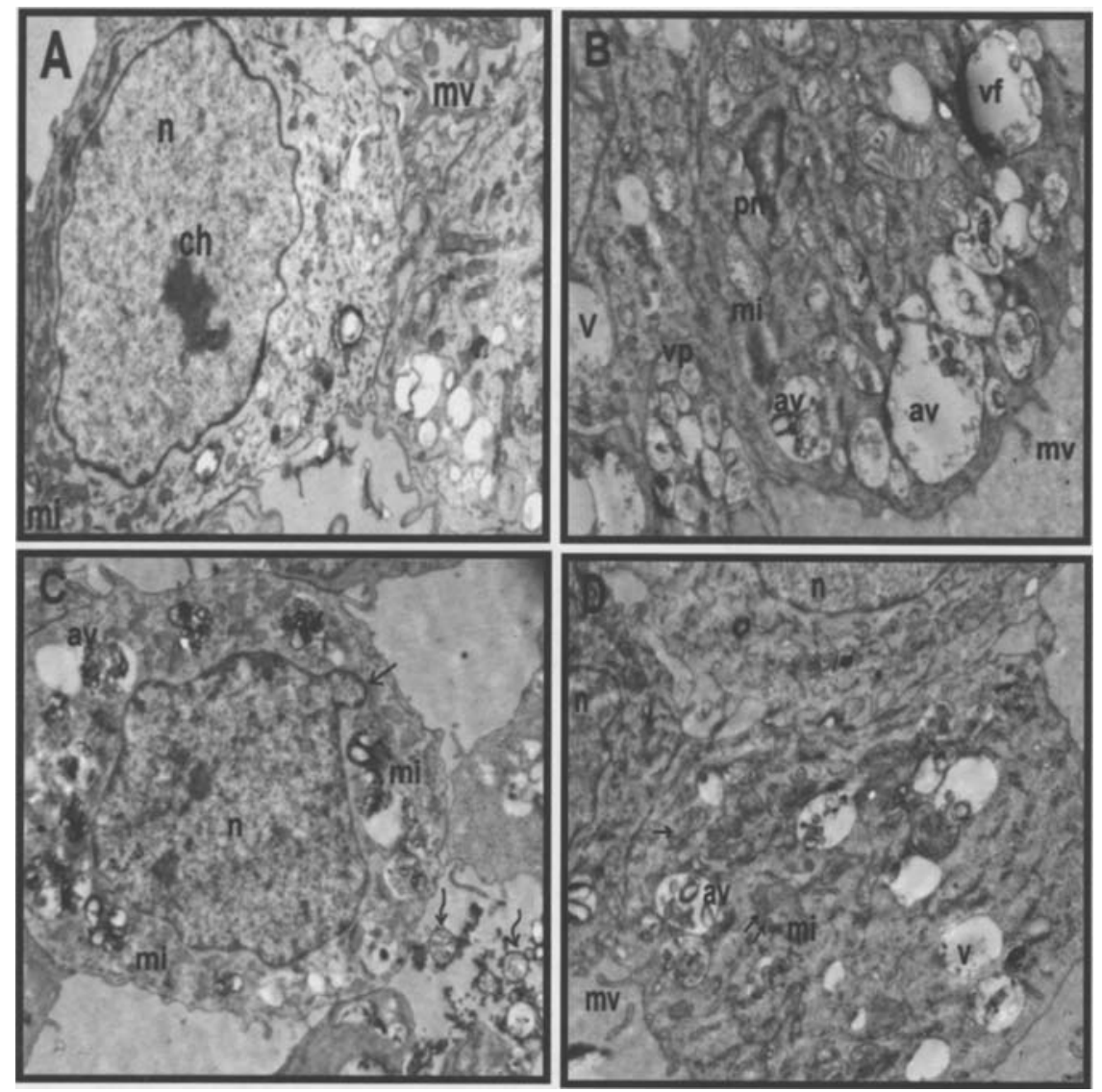

Figure 6. Transmission electron microscopy (TEM) view of C6 glioma spheroids at $96 \mathrm{~h}$. (A) Control group (original magnification, x15000). (B) Imatinib group (original magnification, x6000). (C) Chlorimipramine group (original magnification, x12000). Wavy arrow represents the separation point of cell from the proliferation zone of spheroid. (D) Imatinib with chlorimipramine (original magnification, x5000). av, autophagic vacuole; er, endoplasmic reticulum; $\mathrm{n}$, nucleus; mi, mitochondria; mv, microvillus; $\mathrm{v}$, vacuole; vp, package of vacuoles.

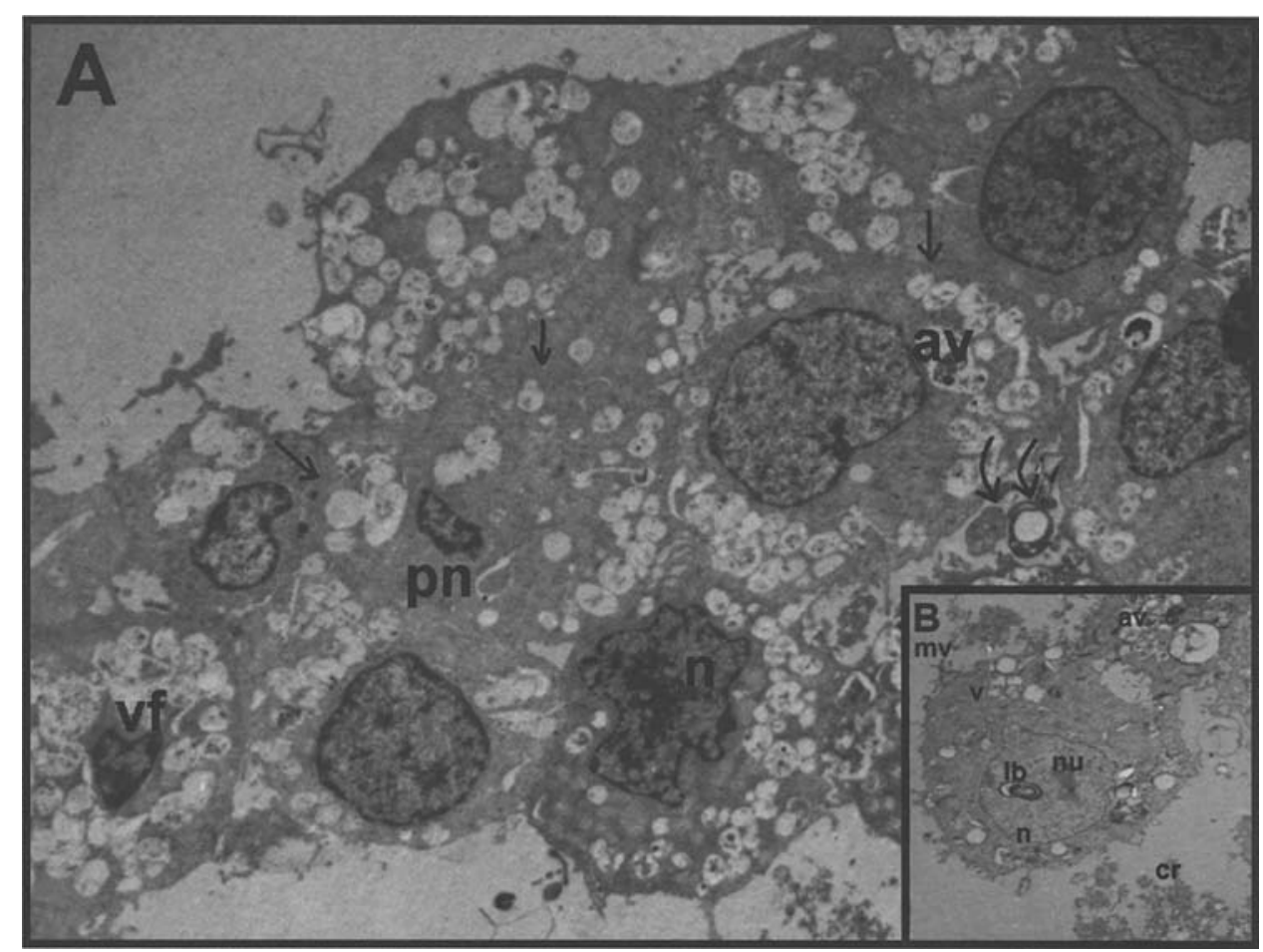

Figure 7. Transmission electron microscopy (TEM) view of C6 glioma spheroids at $96 \mathrm{~h}$. Imatinib with chlorimipramine (original magnification, x4000). (A) One arrow represents the plasma membrane fusion. Wavy arrows represent presumably the apoptotic bodies. (B) The presence of big lamellar body in the nucleoplasm (original magnification, x5000). av, autophagic vacuole; cr, remnants of cell; er, endoplasmic reticulum; lb, lamellar body; n, nucleus; nu, nucleolus; mi, mitochondria; mv, microvillus; v, vacuole; vp, package of vacuoles. 

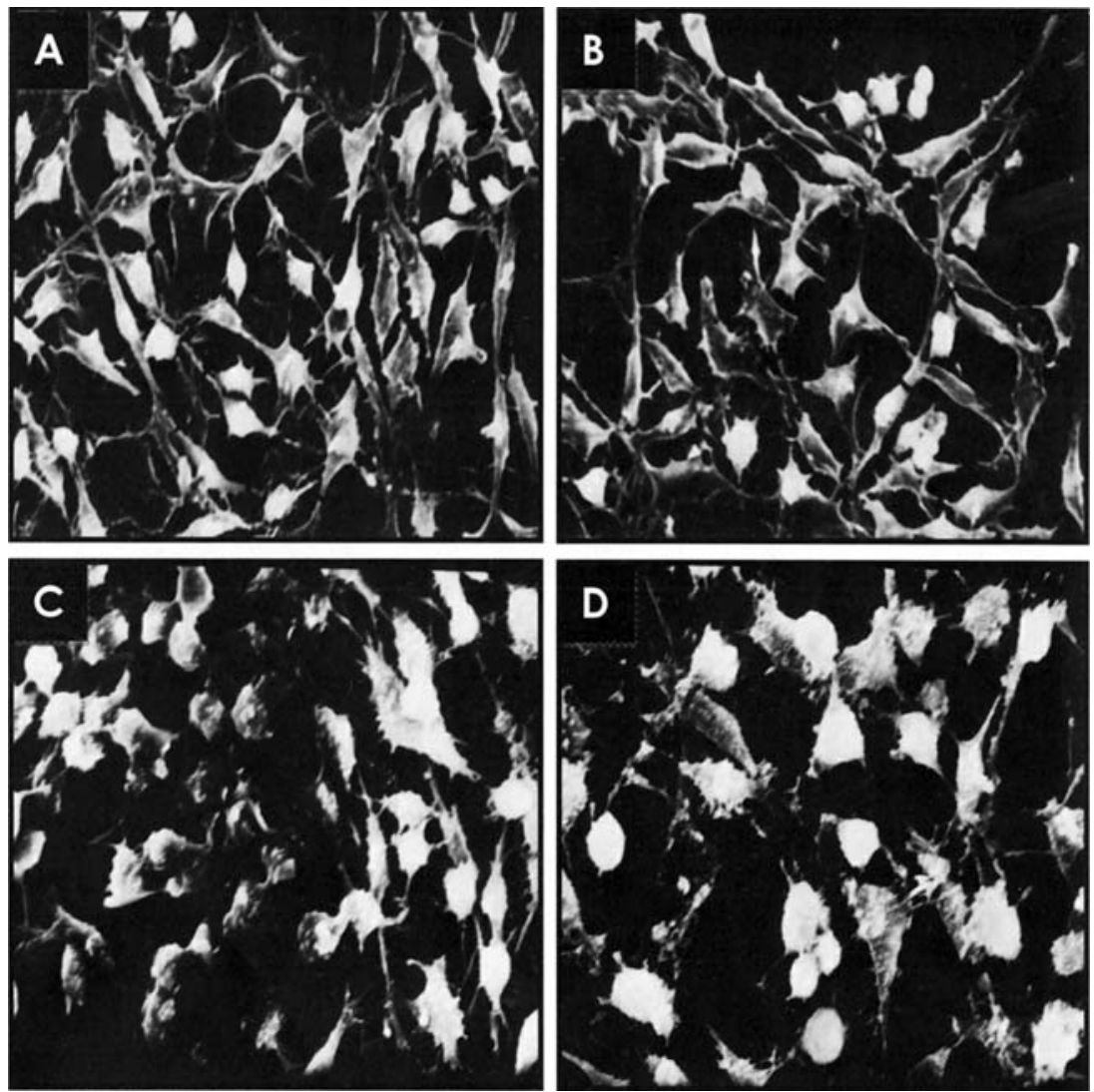

Figure 8. Scanning electron microscopy (SEM) view of monolayer cultured C6 glioma cells at 96 h. (A) Control group (original magnification, x750), (B) Imatinib group. Arrow represents cells which possess extended and angular body (original magnification, x750). (C) Chlorimipramine group. Double arrows represent cells which possess globular appearance like a ball with short cell surface knobs characterized by protruding surface (original magnification, $\mathrm{x} 1000$ ). (D) Imatinib with chlorimipramine. Long arrow indicates the cell type which possesses no specific appearance with protruding surface (original magnification, $\mathrm{x} 1000$ ).

was observed by the combination group represented the enhanced cytotoxicity of IM.

96 of culture. Healthy C6 glioma cells which were in a spindle-shaped appearance were observed in the control group (Fig. 8A). In the IM group, many cells possessed an angular morphology and IM led to a sharp decrease in the number of microvilli and cell surface knobs, which caused an appearance like a protruding surface (Fig. 8B). In the CIMP group, many cells changed to possess a globular appearance like a ball with short cell surface knobs characterized by a protruding surface (Fig. 8C). In the combination group, three different cell types were observed as follows: i) a wide body with an angular morphology with short cell surface extensions; ii) a globular appearance like a ball with short extensions; and iii) no specific appearance with cell surface extensions or with a protruding surface (Fig. 8D).

\section{Discussion}

The treatment of maligant brain tumor glioblastoma multiforme with effective chemotherapeutic regimens remains a challenge. One of the most promising developments in chemotherapy has been to substitute cytotoxic agents that inhibit non-specific targets in cellular pathways that contribute to carcinogenesis and resistance $(25,26)$. It has been reported that IM inhibits the growth of glioma cells in preclinical models, but its poor brain distribution by $\mathrm{P}$-gp limits its efficacy in patients (34). In this study, we investigated whether CIMP, which has a specific effect on mitochondria, could increase the cytotoxic effect of IM.

In the present study, treatment with IM and CIMP in combination was slightly better than single agents using both monolyaers and spheroid cultures of malignant C6 glioma cells. The results of the present study did not fully support the hypothesis that CIMP could induce a synergistic effect on IM-induced cytotoxicity. By using a number of different techniques, the effect of CIMP on IM toxicity on C6 glioma cells revealed the following: i) the effect of the combination group on cell proliferation was synergistic at $96 \mathrm{~h}$; ii) the cell viability results were additive only at $48 \mathrm{~h}$; iii) the decrease of BrDU-LI represented a synergistic effect at 24 and $72 \mathrm{~h}$; iv) the decrease in the percentage of spheroid culture cells in S-phase; v) reduced cAMP levels; and vi) the combination group represented a synergisitc effect in apoptosis. In addition, for autophagy, the results varied from IM as single agent to IM with CIMP in combination and resulted in two different findings: single IMP treatment led to chemoresistance/cell survival and the combination of IM and CIMP led to apoptosis.

The most interesting findings of the present study was determined by transmission electron micrographs of spheroids were the apoptosis results. The combination treatment showed a significant potentiation of apoptosis as compared to 
single agent treatment alone and the alteration of autophagic vacuole-like structures under CIMP treatment. There are no previous reports on the effect of CIMP on autophagy and our data link, for the first time, the process of autophagy with the mode of action of CIMP. Another interesting finding came from the micrographs of CIMP, when CIMP was applied with IM, the cell membranes fused to form a unique membrane surrounding the spheroid exterior (Fig. 6A). The increased autophagy and the presence of membrane fusion in the combination group could be interpreted as synergistic.

Another noteworthy finding from the transmission electron micrographs was the effects of IM, CIMP and the combination group on apoptosis in C6 glioma cells by using Annexin V-FITC and PI double staining. Results showed that IM increased the fraction of apoptotic cells very slightly and CIMP markedly induced and increased apoptosis at all time intervals. However, the findings with the combination group were somewhat surprising; although a low apoptotic fraction in the IM group and a high apoptotic fraction in the CIMP group were observed, the weak effect of IM on the induction of apoptosis, in accordance with the results of transmission electron micrographs, interest was increased by CIMP in the combination group. The effect of CIMP on the apoptotic index was more potent when it was combined with IM. These findings suggested that the two drugs synergize with each other. In addition to TEM micrographs of spheroids, the scanning electron micrographs of monolayer cultured cells supported the increase in the apoptotic index by the combination group. These findings supported the synergistic effect of CIMP on IM-induced toxicity.

In addition, the alterations in cAMP levels of cells also supported the morphologic findings about CIMP-induced mitochondrial damage. C6 glioma cells possess native functional PDGFRs, proliferate in response to PDGF, whose stimulation leads to a well-expressed cAMP and is the first identified second messenger $(35,36)$. The different receptors, chiefly the G-protein coupled receptors and growth factor receptors are responsible for cAMP accumulation in cells that cause different physiologic outcomes, and changes in cAMP levels effect the selective activation of cAMP-dependent protein kinase-A isoforms. The chief source of cAMP is from ATP, which is generated by mitochondria $(37,38)$. In our study, the effective inhibiton of cAMP levels was observed with the CIMP group for all time intervals, but IM showed its inhibitory effect at $72 \mathrm{~h}$. The inhibitory effect of the combination group on cAMP levels also increased at $72 \mathrm{~h}$. The alterations of cAMP levels could also be interpreted as the inhibitory effect of IM on growth factor receptors, such as PDGFR.

Spheroids are known to be in vivo-like tissue-culture representatives and the most adapted model to keep the in vitro resistance properties of cells. Spheroids more closely mimic the real biologic environment by providing cell-to-cell adhesion and signalling. Due to these characteristics, spheroids quite realistically represent the results of the drug effects by including limitations in penetration, distribution, and feedback mechanisms in cell signaling $(39,40)$. In this study, similar to the BrDU-LI results of monolayer cultures, all drug applications reduced the BrDU-LI in comparison to the controls. In comparison to the effects of singly applied drugs, little more decrease in BrDU-LI was observed in the combination group. The effect of CIMP could not be defined as antagonistic, additive, or synergistic, although a strong synergistic effect was observed in transmission electron micrographs of spheroids. The prominent morphologic changes were observed in the spheroid micrographs, but the combination group seemed ineffective in reducing cells in $\mathrm{S}$-phase. Because spheroids are the bridge between in vitro and in vivo, these findings suggest that further studies (i.e., high dose applications) should be done to achieve the effectiveness of these drugs in the spheroid model.

Alterations of spheroid morphology revealed that IM induced and increased the cellular autophagy machinery in our study. Taken together, in the present study, especially in light of findings of electron micrographs with Annexin VFITC and PI double staining and cAMP results together, the effect of IM could be interpreted in two different ways: i) three different studies regarding the IM effect on autophagy were done by Ertmer et al $(41)$ and Carew et al $(42,43)$. Ertmer et al (41) described, for the first time, the process of autophagy with the mode of action of IM. They considered that autophagy may promote apoptosis in cancer cells. They revealed that the IM dose-dependently activates the cellular autophagy machinery in mammalian cells, independently of tissue type, species origin, or the immortalization status of cells. When IM was used in combination, the induction of autophagy by IM might represent an additional mechanism to induce apoptosis in C6 glioma cells, like the study of Ertmer et al (41). Besides, if the mode of action of CIMP was evaluated, the induction of autophagy by CIMP might represent an additional mechanism of CIMP to induce growth arrest and promote apoptosis in C6 glioma cells and this effect of this drug was prominently seen in the combination group. ii) In contrast to Ertmer et al $(41)$, Carew et al $(42,43)$ considered that autophagy may promote cancer cell survival and play important roles in chemoresistance of cancer to some therapeutic agents, which typically induce an apoptotic response. They showed that disrupting autophagy augmented the anticancer activity of the histone deacetylase (HDAC) inhibitor suberoylanilide hydroxamic acid (SAHA) in IMrefractory chronic myelogenous leukemia (CML) and in IM-resistant primary CML cells from patients bearing mutations in Bcr-Abl, including the T315I mutation that causes resistance to currently utilized tyrosine kinase inhibitors and translates into a very poor clinical prognosis $(41,42)$. When IM is used singly, as shown by Carew et al $(42,43)$ the induction of autophagy in the IM-applied group might represent chemoresistance of $\mathrm{C} 6$ glioma cells to this drug.

In contrast to the findings of electron micrographs, Annexin V-FITC and PI double staining, cAMP levels, cell viability, and proliferation (Fig. $1 \mathrm{~A}$ and $\mathrm{B}$ ), and the BrDU-LI of spheroids (Fig. 2) did not indicate that the combination is more potent than the single agent alone, with minor exceptions. The findings that showed the efficiency of the combination group vs. single applications could be hypothesized to be related to CIMP's action: CIMP penetrates plasma membranes easily because of its lipophilic structure (44). Xia et al (45) showed that CIMP induced apoptosis in CML HL-60 cells via increased ROS generation, which 
was followed by an increase of caspase- 3 activity. They proposed that CIMP enhanced the level of ceramide which was involved in ROS production by interacting with complex III of the ETC. Likewise, Xia et al (45) and Levkovitz et al (46) found CIMP to induce apoptosis in C6 glioma caspase-3like activation and cyt-C-release. Daley et al (47) studied the mode of action of CIMP in primary cultures of glioblastoma taken from human biopsies and found that CIMP killed cells through inhibiting glioma cell oxygen comsumption by binding complex III, resulting in caspase-3 activation. In the present study, CIMP could kill C6 glioma cells through a mitochondria-dependent fashion, as indicated in studies above. P-gp is a transmembrane protein that engages in drug efflux in an ATP-dependent fashion. This transports serine or threonine phosphorylation sites which were phosphorylated by several kinases such as PKC- and cAMP-dependent protein kinase (46). IM is a substrate for P-gp (12). CIMP inhibited ATP production via inhibition of mitochondrial respiration and this resulted in the inhibition of cAMP production. In the present study, CIMP was able to faciliate the penetration of IM through the inhibition of P-gp.

Although, CIMP is not considered as a typical chemotherapeutic drug, the present study did not completely substantiate the synergistic cytotoxic effect of IM combined with CIMP on C6 glioma cells and a spheroid model. Briefly, CIMP appears to act with IM only in monolayer cultures of C6 glioma cells, with few exceptions. Further studies should be done to provide the basis for a possible use of IM and CIMP in combination in vivo and to consider CIMP as 'a promising compound' for overcoming IM resistance in the treatment of glioblastoma.

\section{Acknowledgements}

The authors thank Fusun Oncu for technical assistance of cell cultures and Ebru Karabulut for TEM. The present work was supported by the Research Fund of Istanbul University with the project number 484/05052006 and IM was provided by Novartis AG, Basel, Switzerland. This work was done at Istanbul University Istanbul Faculty of Medicine in the Histology and Embryology Department Cell and Tissue Culture Laboratory.

\section{References}

1. Arora A and Scholar EM: Role of tyrosine kinase inhibitors in cancer therapy. J Pharmacol Exp Ther 315: 971-979, 2005.

2. Heinrich MC, Blanke CD, Druker BJ and Corless CL: Inhibition of KIT tyrosine kinase activity: a novel molecular approach to the treatment of KIT-positive malignancies. J Clin Oncol 20: 1692-1703, 2002.

3. Buchdunger E, Cioffi CL, Law N, et al: Abl protein-tyrosine kinase inhibitor STI571 inhibits in vitro signal transduction mediated by c-kit and platelet-derived growth factor receptors. J Pharmacol Exp Ther 295: 139-145, 2000.

4. Yu C, Krystal G, Dent P and Grant S: Flavopiridol potentiates STI571-induced mitochondrial damage and apoptosis in BCR-ABL-positive human leukemia cells. Clin Cancer Res 8: 2976-2984, 2002.

5. Uziel O, Fenig E, Nordenberg J, et al: Imatinib mesylate (Gleevec) downregulates telomerase activity and inhibits proliferation in telomerase-expressing cell lines. Br J Cancer 92: 1881-1891, 2005.

6. Deininger M, Buchdunger E and Druker BJ: The development of imatinib as a therapeutic agent for chronic myeloid leukemia. Blood 105: 2640-2653, 2005.
7. Tarn C, Skorobogatko YV, Taguchi T, Eisenberg B, von Mehren $\mathrm{M}$ and Godwin AK: Therapeutic effect of imatinib in gastrointestinal stromal tumors: AKT signaling dependent and independent mechanisms. Cancer Res 66: 5477-5486, 2006.

8. Kilic T, Alberta JA, Zdunek PR, et al: Intracranial inhibition of platelet-derived growth factor-mediated glioblastoma cell growth by an orally active kinase inhibitor of the 2-phenylaminopyrimidine class. Cancer Res 60: 5143-5150, 2000.

9. Krystal GW, Honsawek S, Litz J and Buchdunger E: The selective tyrosine kinase inhibitor STI571 inhibits small cell lung cancer growth. Clin Cancer Res 6: 3319-3326, 2000.

10. Mitsiades CS, Sykoutri D, McMullan C, Poulaki V and Mitsiades N: Effect of imatinib mesylate (Gleevec) on anaplastic thyroid carcinoma cell lines. J Clin Endocrinol Metab 88: 5043-5044,2003.

11. Kim SJ, Uehara H, Yazici S, et al: Targeting platelet-derived growth factor receptor on endothelial cells of multidrug-resistant prostate cancer. J Natl Cancer Inst 98: 783-793, 2006.

12. O'Reilly T, Wartmann M, Maira SM, et al: Patupilone (epothilone B, EPO906) and imatinib (STI571, Glivec) in combination display enhanced antitumour activity in vivo against experimental rat C6 glioma. Cancer Chemother Pharmacol 55: 307-317, 2005.

13. Lokker NA, Sullivan CM, Hollenbach SJ, Israel MA and Giese NA: Platelet-derived growth factor (PDGF) autocrine signaling regulates survival and mitogenic pathways in glioblastoma cells: evidence that the novel PDGF-C and PDGF-D ligands may play a role in the development of brain tumors. Cancer Res 62: 3729-3735, 2002.

14. Breedveld P, Pluim D, Cipriani G, et al: The effect of Bcrp1 (Abcg2) on the in vivo pharmacokinetics and brain penetration of imatinib mesylate (Gleevec): implications for the use of breast cancer resistance protein and P-glycoprotein inhibitors to enable the brain penetration of imatinib in patients. Cancer Res 65: 2577-2582, 2005

15. Hagerstrand D, Hesselager G, Achterberg S, et al: Characterization of an imatinib-sensitive subset of high-grade human glioma cultures. Oncogene 25: 4913-4922, 2006.

16. Trimble MR: Worldwide use of clomipramine. J Clin Psychiatry 51 (suppl): 51-58, 1990.

17. Steingart $\mathrm{AB}$ and Cotterchio $\mathrm{M}$ : Do antidepressants cause, promote, or inhibit cancers? J Clin Epidemiol 48: 1407-1412, 1995.

18. Sauter C: Cytostatic activity of commonly used tricyclic antidepressants. Oncology 46: 155-157, 1989.

19. Merry S, Hamilton TG, Flanigan P, Freshney RI and Kaye SB: Circumvention of pleiotropic drug resistance in subcutaneous tumours in vivo with verapamil and clomipramine. Eur J Cancer 27: 31-34, 1991.

20. Rooprai HK, Christidou M and Pilkington GJ: The potential for strategies using micronutrients and heterocyclic drugs to treat invasive gliomas. Acta Neurochir (Wien) 145: 683-690, 2003.

21. Xia Z, Lundgren B, Bergstrand A, De Pierre JW and Nassberger L: Changes in the generation of reactive oxygen species and in mitochondrial membrane potential during apoptosis induced by the antidepressants imipramine, clomipramine and citalopram and the effects on these changes by Bcl-2 and Bcl-X(L). Biochem Pharmacol 57: 1199-1208, 1999.

22. Daley E, Wilkie D, Loesch A, Hargreaves IP, Kendall DA, Pilkington GJ and Bates TE: Chlorimipramine: a novel anticancer agent with a mitochondrial target. Biochem Biophys Res Commun 328: 623-632, 2005.

23. Castaing M, Brouant $\mathrm{P}$, Loiseau A, et al: Membrane permeation by multidrug-resistance-modulators and non-modulators: effects of hydrophobicity and electric charge. J Pharm Pharmacol 52: 289-296, 2000.

24. Pommerenke EW and Volm M: Reversal of doxorubicinresistance in solid tumors by clomipramine. In Vivo 9: 99-101, 1995.

25. Sathornsumetee S, Reardon DA, Desjardins A, Quinn JA, Vredenburgh JJ and Rich JN: Molecularly targeted therapy for malignant glioma. Cancer 110: 13-24, 2007.

26. Widakowich C, De Azambuja E, Gil T, et al: Molecular targeted therapies in breast cancer: Where are we now? Int $\mathbf{J}$ Biochem Cell Biol (In press).

27. Altinoz MA, Bilir A, Del Maestro RF, Tuna S, Ozcan E and Gedikoglu G: Noscapine and diltiazem augment taxol and radiation-induced S-phase arrest and clonogenic death of C6 glioma in vitro. Surg Neurol 65: 478-485, 2006. 
28. Kaygisiz Z, Erkasap N, Yazihan N, et al: Erythropoietin changes contractility, cAMP and nitrite levels of isolated rat hearts. J Physiol Sci 56: 247-251, 2006.

29. Harper JF, Brooker G, Harper JF, et al: Femtomole sensitive radioimmunoassay for cyclic AMP and cyclic GMP after $2^{\prime} 0$ acetylation by acetic anhydride in aqueous solution. J Cyclic Nucleotide Res 1: 207-218, 1975.

30. Ugur O and Onaran HO: Allosteric equilibrium model explains steady-state coupling of $\beta$-adrenergic receptors to adenylate cyclase in turkey erythrocyte membranes. Biochem J 323: 765-776, 1997.

31. Chou TC and Talalay P: Quantitative analysis of dose-effect relationships: the combined effects of multiple drugs or enzyme inhibitors. Adv Enzyme Regul 22: 27-55, 1984.

32. Chou TC and Talalay P: Analysis of combined drug effects: a new look at a very old problem. Trends Pharmacol Sci 4: 450-454, 1983.

33. Sacks PG, Harris D and Chou TC: Modulation of growth and proliferation in squamous cell carcinoma by retinoic acid: a rationale for combination therapy with chemotherapeutic agents. Int J Cancer 61: 409-415, 1995.

34. Dai $H$, Marbach $P$, Lemaire $M$, Hayes $M$ and Elmquist WF: Distribution of STI-571 to the brain is limited by P-glycoprotein-mediated efflux. J Pharmacol Exp Ther 304: 1085-1092, 2003.

35. Sokolowska P and Nowak JZ: Constitutive activity of betaadrenergic receptors in C6 glioma cells. Pharmacol Rep 57: 659-663, 2005.

36. Grobben B, De Deyn PP and Slegers H: Rat C6 glioma as experimental model system for the study of glioblastoma growth and invasion. Cell Tissue Res 310: 257-270, 2002.

37. Jaiswal BS and Conti M: Calcium regulation of the soluble adenylyl cyclase expressed in mammalian spermatozoa. Proc Natl Acad Sci USA 100: 10676-10681, 2003.
38. Baillie GS and Houslay MD: Arrestin times for compartmentalised cAMP signalling and phosphodiesterase- 4 enzymes. Curr Opin Cell Biol 17: 129-134, 2005.

39. Takagi A, Watanabe M, Ishii Y, et al: Three-dimensional cellular spheroid formation provides human prostate tumor cells with tissue-like features. Anticancer Res 27: 45-53, 2007.

40. Sutherland R, Carlsson J, Durand R and Yuhas J: Spheroids in cancer research. Cancer Res 41: 2980-2984, 1981.

41. Ertmer A, Huber V, Gilch S, et al: The anticancer drug imatinib induces cellular autophagy. Leukemia 21: 936-942, 2007.

42. Carew JS, Nawrocki ST and Cleveland JL: Modulating autophagy for therapeutic benefit. Autophagy (In press).

43. Carew JS, Nawrocki ST, Kahue CN, et al: Targeting autophagy augments the anticancer activity of the histone deacetylase inhibitor SAHA to overcome Bcr- Abl-mediated drug resistance. Blood (In press).

44. Lainesse C, Frank D, Meucci V, Intorre L, Soldani G and Doucet M: Pharmacokinetics of clomipramine and desmethylclomipramine after single-dose intravenous and oral administrations in cats. J Vet Pharmacol Ther 29: 271-278, 2006.

45. Xia Z, Bergstrand A, De Pierre JW and Nassberger L: The antidepressants imipramine, clomipramine, and citalopram induce apoptosis in human acute myeloid leukemia HL-60 cells via caspase-3 activation. J Biochem Mol Toxicol 13: 338-347, 1999.

46. Levkovitz Y, Gil-Ad I, Zeldich E, Dayag M and Weizman A: Differential induction of apoptosis by antidepressants in glioma and neuroblastoma cell lines: evidence for p-c-Jun, cytochrome c, and caspase-3 involvement. J Mol Neurosci 27: 29-42, 2005.

47. Daley E, Wilkie D, Loesch A, Hargreaves IP, Kendall DA, Pilkington GJ and Bates TE: Chlorimipramine: a novel anticancer agent with a mitochondrial target. Biochem Biophys Res Commun 328: 623-632, 2005.

48. Ramakrishnan P: The Role of P-glycoprotein in the Blood-Brain Barrier. Einstein Q J Biol Med 19: 160-165, 2003. 